$$
\text { th. } 275 \% \text { orNL-5537 }
$$

\title{
Thermodynamics of Precipitation Systems
}

R. O. Williams 


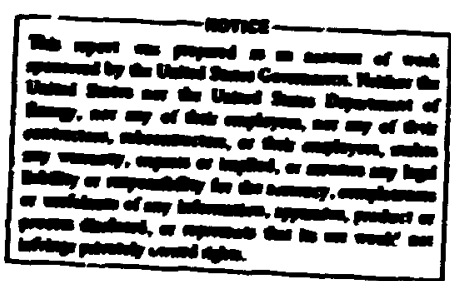

Date Publ1shed - June 1979

OAR RIDGE MTIONAL LABCRATORY

Oak R1dge, Tennessee 37830

operated by

UHION CARBIDE CORPORATION

for the

DEPARTMENT OP ENERGY

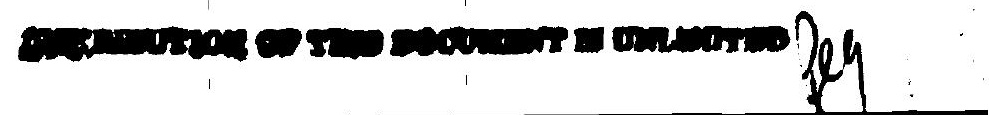




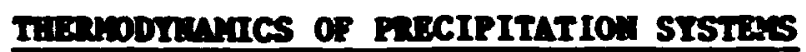

R. 0. Hilleas

ARSTRACT

The particular combination of features that are required for a binary systen to show useful precipitation hardening is exmined. Decunse this conbination is relatively rare, we are not optinistic that any useful binary sjstens realn to be discovered. When one goes to higher order syatens case has nuch greater opportunities for developing weful syetens because of the increased degrees of freedon. The difficulty of uoderstandins wat is happening is aloo correopoodingly greater, but if it is poselble to properly represent the thercodjnenics of the ojoten, then this problen can be resolved. Considerable potential is belleved to exist for the development of new alloye containing three or sore composents.

\section{ImTRODUCTIOA}

It Is very well known that the first prerequisite for precipitation hardening is a decreasing solubllity with decreasing temperature. Sluce this occurs unlvcrally as a result of the decreasing inportance of the entropy of aixing with decreasing temperatures, one way wil sak thy there are not a large muber of useful precipitation ojoteas. In this paper we w11 exanine what eupplementary conditions are also necesary and show that the thermodyrenics of useful oystens is conewhat unueual. Fron this understanding we should be able to predict the usefulness 0 : a spectfic binary eyster from its phace diagran and etructural infornation. But we do not expect that any useful binary systens reanin to be discovered.

When we 80 to eystens wth we components the stcuacion takes on new complexity atched by expanded opportunities for precipitation hardening. The problen 1o In understanding thece core conplex syotens in order to predict where useful compostions are to be found. This report shown how the problea can ide addrased. 
ATRIDUTES OP A USEPUL 3TSTEA

A useful wolune of the second phase, typically in excess of 17 , nust be able to form when the anterial is quenched from elevated terperatures and subsequently aged at sone suitable tenperature, norally a iesperature above the desired service teaperature. The precipitation nust be, oufficiently rapid that the optim properties can be obtained In lese that $24 \mathrm{~h}$. The new phase nust be finely dispersed, as in particles $10 \mathrm{~m}$ in dianeter. This requires that the particles and the natrix must be cohereat because this degree of dispersion requires bongeneous nucleation and homogeneous nucleation of incoherent particles is unknown. In general, the two lattces will not atch perfectly; thus the coherency will lead to some strain energy, which can be an iaportant source of strengthening. This requirenent of coberency linits the difference that can exist between the two structures. If the two lattices are basically the sase, then a coherent prEcipitate ay forn if the difference between the lattice paraneters dows not exceed 10\%. Further, a coherent hcp precipitate can form in an fce lattice on the (111) habit plane provided the alsatch is sinflarly linited. This probably occurs on dislocation loops resulting from vacancy precipitation and thus is honggeneous precipitation in a restricted sense. Coherency betmeen bcc and fec or hep lattices does not occur axcept possibly under extrene degrees of euperaturation.

The preserce of order in the precipitate provides an inportant source of strengthening, and in the absence of coberency stresses this ordering is escential if useful strengthening is to be achieved. A further adventage of using ordered particles for strengthening rather than coherency etrains is that wich otralne necesearily contribute to Instabllity of the systen; the presence of order does. not. 
For our purpose the free energy of a solution having the a strurture is representable as

$$
G_{a}=\sum_{i \neq j} \frac{x_{i}^{2} x_{j}}{x_{i}+x_{j}} \phi_{i j}+\sum x_{i}\left(G_{i}+R I \ln x_{i}\right),
$$

where

$x_{i}=$ the aton fraction of the $i$ th component,

$\phi$ = a heat of alxing paraneter,

$G_{i}=$ the free energy of pure $i$ th conponel. relative to its standard state.

Kaufaan calls these the lattice stability paraneters. This representation is known as the Rohler fornula.l

The serlous reader should have a reasonably good grasp of the neaning of this equation. For this purpose we show in Fig. 1 a set of

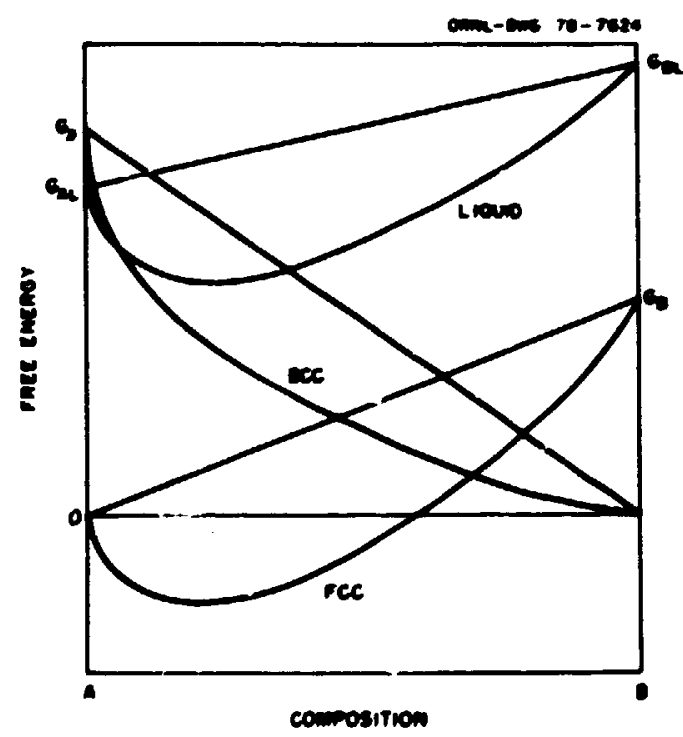

P18. 1. Pree Energy Curves for a Binary Systen In Which the Structure of the Two Components is Different.

1P. Kohler, Nonatih. Chem. 91: 738-40 (1960). 
free energy curves, wich aight represent a binary eutectic systen bereen terninal phases of different structures. The meaning of $\mathcal{G}_{B}$ is simply the free energy required to convert $B$ from the stable $\beta$ strunture to the a structure. Tinere is an analogous tern for the component $A$ and two sinilar terns for liquids $A$ and $B$. Of ten the free energy curves are symetric (when the lattice stabllity terns are ignored) such that $\phi_{i j}=j i$; such solutions are normally called regular. Frequently the equality does not hold, as is the case illustrated. Hore generally the \$s ull have a teaperature dependence representing a tenperaturedependent heat of afxing and excess entropy. Lackins such a dependence our expression would correspond to an Ideal entropy of mixing and the $\phi$ reprecent the heat of aixing. Any temperature dependence beyond that Included in Bq. (1) is too anall to drastically change the free energy curves and need not be considered for our present purpose.

Our diagran also represents a useful observation. The free energy curves for the liquid and the three comon solid structures are sinilar in the sense shown. Alnost unfversally, the free energy corve for the liquid is sonewhat nore negative. We should, perhaps, restrict these statements to the kinds of solutions of Interest. here; In the case where the solubilities are very sal.1 because of a large posilive heat of mixing and/or large lattice stabiltty terns we are less sure of the true situation.

This correlation also extends to compound formation in that the wore negative the heat of axing the more likely is compound formation. Compounds are alnost nonexistant in systens having a positive heat of nixing. Por the case of asymetry the compounds are nore likely to occur near the composition where the heat of alxing is nost negative. Al 1 of this weans that the nature of the interactio:l berwen different kinds of wetal atons is not particularly structure sensitive. 
The partial free energy for the ith conponedt in this solution is given as

$$
\begin{aligned}
& \bar{G}_{a i}=F T \text { ln } x_{i}+G_{i}+\sum_{j}\left[\frac{x_{i} x_{j}}{x_{i}+x_{j}}\left(\frac{x_{j}}{x_{i}+x_{j}}+1-x_{i}\right) \phi_{i j}\right. \\
& \left.+\frac{x_{j}^{2}}{x_{i}+x_{j}}\left(\frac{x_{j}}{x_{i}+x_{j}}-x_{i}\right) \phi_{j i}-\sum_{i} \frac{x_{j}^{2} x_{l}}{x_{j}+x_{l}} \phi_{j l}\right]
\end{aligned}
$$

It is important to lote that every term in the first 30 in Eq. (1) is included in this expression. If we have a new phase consisting of $x_{i}$ and $x_{j}$ noies of $i$ and $j$ and having a free energy of $G_{i j}$, then this phase will form If $X_{i} G_{i}+X_{j} G_{j}$ is more positive than $G_{i j}$ the precipitation from the a phase will cease when the equality is obtained. This criterion sinultaneously applies to all possible new phases and can be extended to phases of wore than two components.

It is well known that the coherency energy increases the solubilities; that is, the two-phase fields are reduced in extent. The way in which this effect is to be treated has recently been presented. 2

$A$ few sets of $G$ are known experinentally, but usually they have to be estinated. Values have been provided by Raufaan and Bersteln ${ }^{3}$ and by Michaels et al.4 The $\phi s$ can be deduced from the thernodynanics and from the phase dlagrans. A number of paraneters have been published and the nuber should increase substantially in the future. At the present none of these paraneters have been obtalned from theory with useful accuracy.

2R. 0. M1111ans, Blastic Energy and Mtastable Phsse Equilibria for Coherent Nixtures in Cubic systems, ORNL-5509 (February 1979).

3. Raufaan and H. Bersteln, Computer Calculation of Fhase Diagrans, Academic Press, New York, 1970.

4. F. Michaels et al., "Considerations on the Raufean Approach to Binary Phase Diagran Calculation," Metall. Trane. 6A: 1843-48 (1975). 


\section{BInRI SYSTEas}

For binary alloys the sinplest wy to cover the inportant factors is to exanine various types of binary systeas.

\section{Miscibility Caps}

When the structire of both neabers of a binary pair is the sane and the heat of aixing is positive then there will exist. alscibility gap whose moxim, in Relvins, is nuerically equal to approxinately the axion heat of aixing in calories per sole (about one-fourth that in joules per sole). If the heat of wixing is too positive, the gap will be Incomplete as a result of nelting, as in the Cu-As systen. For coherent precipitation the gap will be suppressed in proportion to the square of the cifferem In lattice paraneters of the two components. In some cases, as the Au- $\mathrm{N}_{1}$ systen, the acount of suppression can be very considerable. Within the coherent gap oae can obtain coherent phase separation, a process terned spinodal decomposition. In sose cases, as the w-Pt and Fe-Cr systens, streagth increases art observed. Perhaps the ast inportant defect of such systens is that the second phase 1s not ordered. Then, the coherency strains ay be too sall to strengthen or too great to pernit precipitation. And further, the gap aay extend to high temperatures and thus restrict the count of the ainor phase or else occur so low in temperature that the aging is too slugsish. In any case such binary systens are of little or no wse.

\section{Binary Butectic Systens}

Bere we are concerned with the cace where the structures of the two netals are different; otherwite they costitute opecial case of the

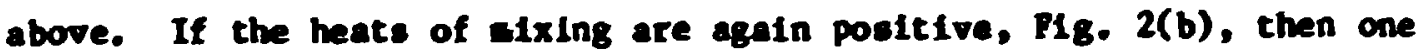



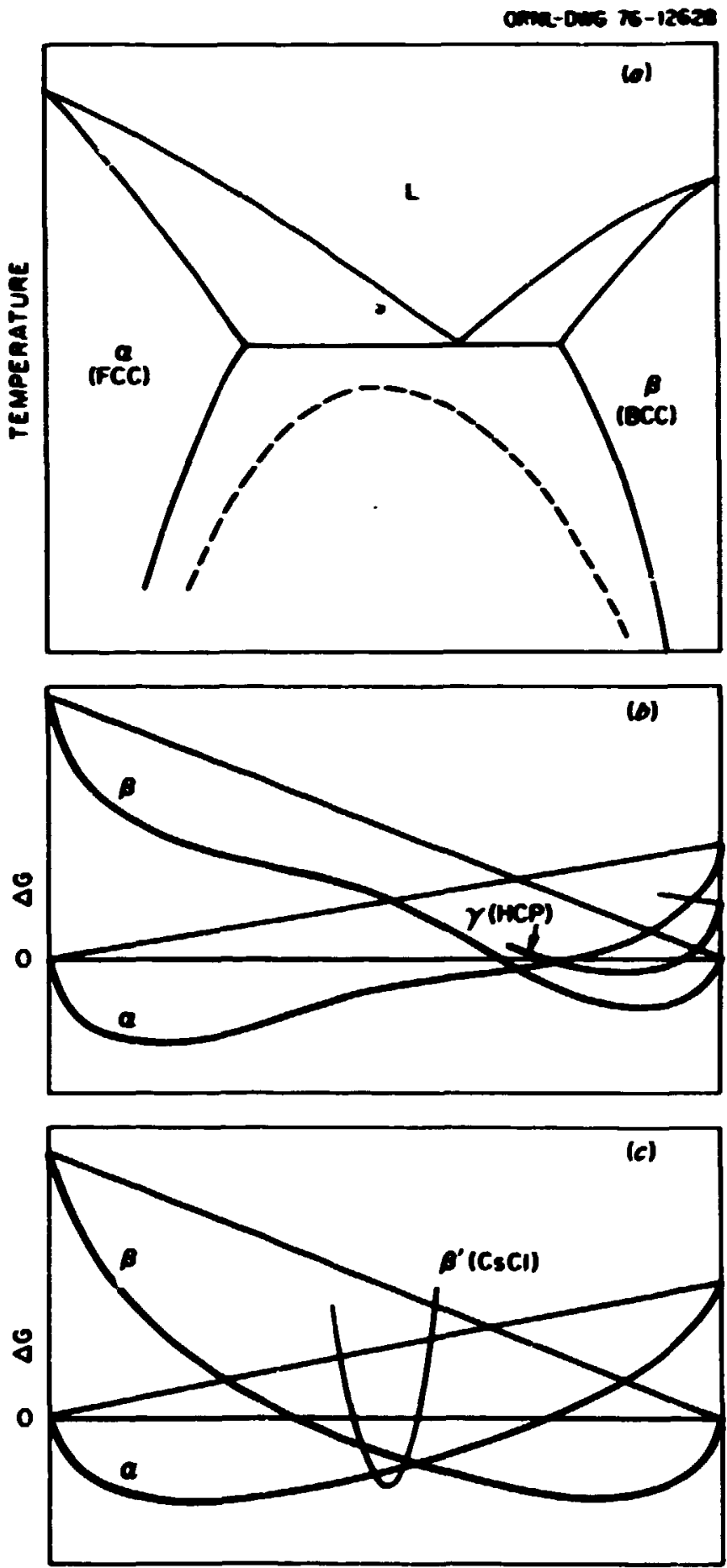

P1g. 2. Possible Pree Energy Curves for a Binary Eutectic Systen for Components with Different structures. If, as in (b), the heat of aixing 1s positive, a metastable alscibility gap can exist. Wo gap can occur for negative heats of aixing, (c), but netastable compounds aight for or, as suggested in (b), a netastable hcp phase alght precipitate fron the fec phase. 
will have uxtastrible decibility gaps, which can leed to decouposition, as considered above, with the poseible important difference that the degree of superaturation is reduced because of the etastability. The Fe-Cu systen is a known case where this type of behavior occurs: one can precipitate bec $\mathrm{Cu}$ in Fe or fcc Pe in $\mathrm{Cu}$.

If the heats of axing are negative, then no metastable gap can exist, but metastable phases might forn, as suggested in Fig. 2 (b and c), which indicates that an bep phase could precipitate in the fec phase or a Cacl structure could precipitate in the bec phase.

Provided the degree of superaturation is sufficlently great, it $\mathrm{my}$ be possible io precipitate coherent $\alpha$ in $\beta$ or vice verea. The case of $\mathrm{Cu}-\mathrm{Cr}$ any buch a case, although the $C r$ could be inttially fcc or bep.

The MI-Cr systen, P18. 3, is a particularly inceresting systen of this type in which the heat of axing for the bec phase is positive, leading to a very high degree of supersaturation, which causes precipitation of $\mathrm{MI}$, presuably a bec structure initially. The heat of aixing for the fcc Mi-rich phase is negative and leads to such a anall degree of supersaturation that fec $\mathrm{Cr}$ does not precipitate. There is an

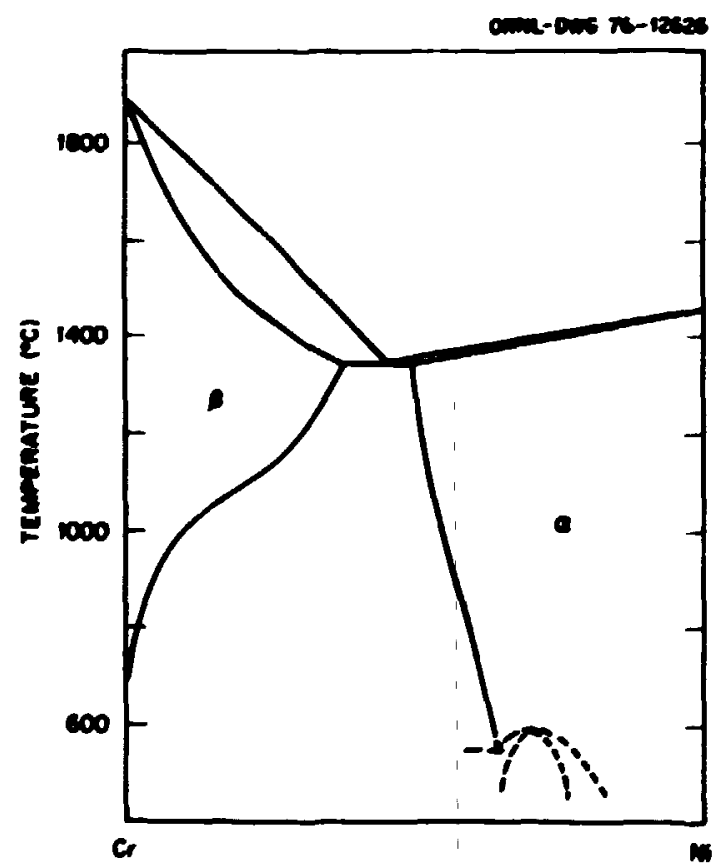

P1g. 3. The Phase Diagran for the Cr-MI Sycten. 
ordering reaction at lower temperatures in this phase, which does display sone strengthening.

The reader should appreciate that that happens in ojsteas of this tjpe is dictated boch by the heats of alxing and the angitudes cf the lattice stabllity terns. For a constant stablitty ewersy differeace it is readily appare.t that increasingly negative values of the beat of aixing increase the terainal solubilities. These higher values alght be vieved as an asset, but, unfortunately, the solublities change less rapidiy with temerature, so the required degree of supereaturation any cot be obtainable.

\section{Compound Formation}

If we have a systen, as shown in F18. 4, chere a mber of conpounds have strongly negative heats of formation, then, In general, weful
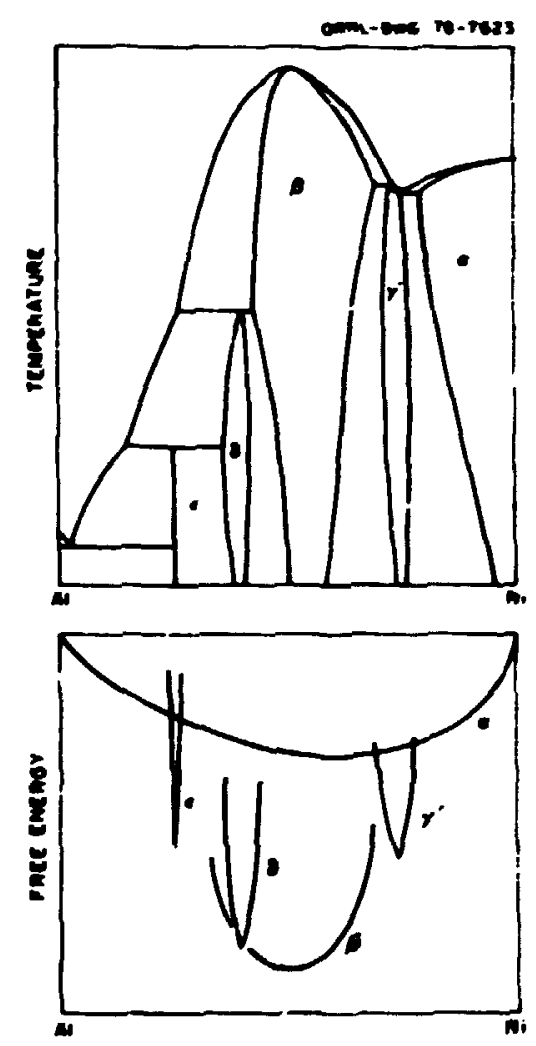

P1g. 4. Phase DLagran and Free Energy Curves for a Cace with Strong Compound Pornation. This diagran is based on the Al-il syste. Por weh systeas it is nornaliy possible to obtaln supersacuration in the cervinal solid solutions only with respect to the ad jacent phase. 
precipitation aight occur in either terninal solid solution. It is litely that. significant supersaturation can be obtained only with respect to the structure in equilibriun with the ternioal phase. This results from the netastable solubility of the internediate phases being large comparec with the equilibriu solubiltties. Whetber or wot such structures precipitate and are useful depends upon the stivctural siatlarity to the tercinal solution. The syste can still fall to provide useful age hardening compositions if elther the anount of precipitate or the degree of superanturation is too anll.

Because the Internediate phases also show narrowing regions cf stability with decreasing tenperature, they night be precipitation strengthened. These possibilities are linited by the sallness of the degree of supersaturation and the inability to achieve s, ersaturation with respect to a suitable structure for homogeneous nucleation. The nuber of comercially inportant alloys based on intecaediate phases 12 very linited, and no case cones to and where the properties are nodified through precipitation.

The Mi-Al systen (F1g. 4) shows too little solubility for the Alrich phase, and for the M-rich end the usefulness is rather arginal because the temperature dependence of the solubility is low.

\section{Asymetric Systens}

In our analysis of binary systems so far we have assuned that the heat of nixing was wore or less symetric. In some inportant cases the heat of alxing is dectdedly asymetric, and this can have Inportant consequences. The nost important case, the Cu-Al system, is shown in P1g. 5 where we see that the heat of als:Ing is rather nore negative on the Curtich end than on the Al-rich end. In the first place the Al-rich colution can becone supersaturated relative to all the intermediate phases, and the one that forms first, $\mathrm{Cu}_{3} \mathrm{Al}$, most resembles the alusinu 1aztice. Supersaturation with respect to th1s phase requires a teaperal:ure somewhat less than that corresponding to Fig. 5. Purther, the assmatry leads to the rapid changes in the solubility in the Al-rich and, a feature that is in large meacure responsible for the utility of 

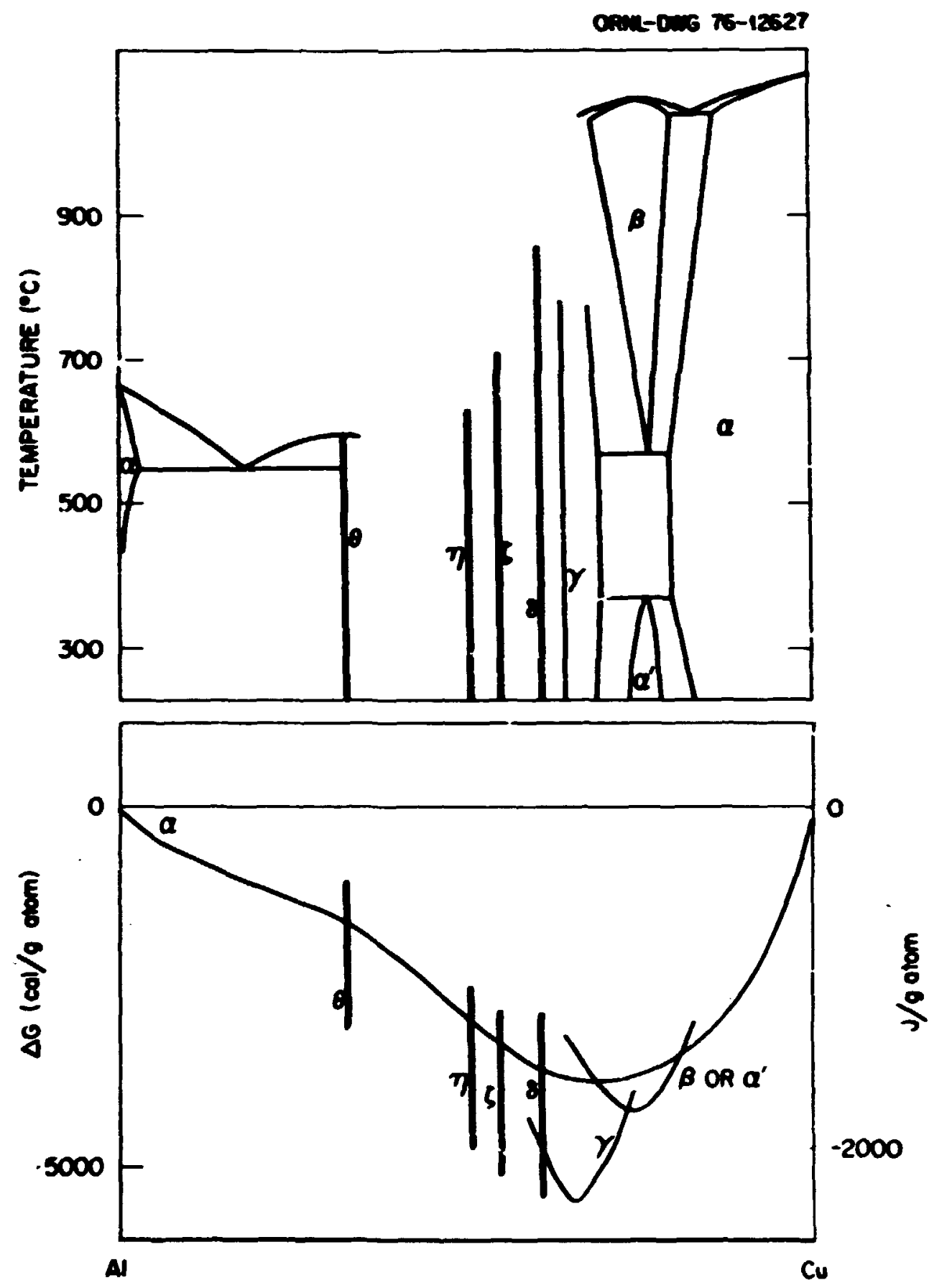

F18. 5. Partial Phase Diagraa and the Free Energy Curves for the A-Cu Systen. Because of the strong asymetry in the free energy of the fcc a phace it is possible to obtain supersaturation with respect to all Internediate phases in the Al-base solid solution. The Initlal precipitate (GP zones) results fron elther spinodal deconposition with1n the wetastable acciblity gap or the formation of $\alpha^{\prime}$, an ordered phase akin ro Cuzhu. 
the systien. The degree of supersaturation in the Cu-rich end is auch lower, and this, coupled with the low tenperatures, akes precipitation unimpoztant in this end of the system. The $\mathrm{N}-\mathrm{Al}$ system also shows sinflar asymetry, but in that case the solubility of $\mathrm{MH}$ in $\mathrm{Al}$ is too low to be of use.

The Al-Ag systen is similar to the Cu-Al system. The Al-rich solution readily forms an $18-$-rich precipitate, which is ordered below $190^{\circ} \mathrm{C}$. After longer tines an hep phase forns; it is still coherent and retains useful levels of strengthening. Precipitation hardening is not known in the Ag-rich end of the systen. The Al-zn systen is also asymetric, but here the fcc $\mathrm{Zn}$-rich precipttate is disordered and the strength levels are rather low.

In sumary, the reasons why binary systens produce such a sall fraction of useful precipitation systens is related to the following:

1. the lack of a suitable prectpitate phase,

2. the inability to obtain the supersaturation required to precipitate the desired phase,

3. too little precipitace,

4. the saallness of the elastic strains and the absence of order, which do not provide useful strength increases.

These factors appear to be of sinilar iaportance.

HIGHER ORDER SYSTEMS

When we 80 to higher order systems a number of things can happen that considerably increase the possibilities for precipitation hardening. The following are known to be iaportant.

The addition of a third element can drastically increase the extent of a miscibility gap; it can create a gap even when none existed in the binaries. 5 This happens, for example, when the heat of mixing is rather

5. L. Heifering, "Segregation in Regular Ternary Solutions, I," Philips Res. Rep. 5: 333 (1950); "..., II," Philipe Ree. Rep. 6: 183 (1951). 
negative for ooe binary but Ideal for the other two. One phase will consist of the solution having the negative heat of alxing and the other phase will be rich in the third component. A negative heat of afring is associated uth short-range order or conpound foration, thus possibly giving enhanced strengthening. As we have seen, this happens in the biary case coly for asymetric systens; asymetric binaries are not required in systens of three or wore components.

The situation is complex, but in general the coherency strains are less in higher order systems. 6 There are always possible sets of tie 1 ines connecting phases of Identical lattice paraneter for which the coherency strains are zero. Purther, the tie lines for coterent phases will tend to rotate from their unstralned equilibriun positions so as to reduce the coherency energy. This effect is Inpossible in binary systens.

The eaximu eatropy of aixing increases with the nuber of conponents, as shown by Bq. (1). This will increase the tenperature dependence of the solubilities.

Precipitate phases that are Inpossible in the binaries can form. An $A 1$ alloy wth $\mathrm{Hg}$ and $\mathrm{SI}$ is an example. Individually, $\mathrm{H}_{8}$ and $\mathrm{SI}$ impart linited age hardening capacity, but together they precipitate $\mathrm{H}_{2} \mathrm{Si}$, which gives enhanced properties. Ternary conpounds are known with no counterpart in the binaries, but they are rather rare. In fact, while comercial alloys alnost invariably contain three or more components, only two cases cone to and where ternary compounds are known to be Important. These occur In aluinu alloys that contain $\mathrm{H}_{\mathrm{B}}$ and $\mathrm{Cu}$ or $\mathrm{zn}$. Supereaturated solid solutions can de:onpose by means of cellular or discontinuous precipitation, but properties are not enhanced because the resulting mixture is rather codrse. It has been proposed that large degrear fi elastic strain energy enhance thy process by suppressing the coherent aiscibility gap.6 since this cohercucy energy can be reduced In higher order systens, It should be possible to reduce the inportance of cellular precipitation in such cases.

6R. 0. Willians; "Stability of the Body Centered Cubic Gana Phase in the Uraniu-Zirconiun-Niobtu Systed," Joumal of Nuclear Materiale (in press). 
It is beyond the scope of this report to try to systematize the possibilities for obtaining useful precipitation in higber orcer systess apart fron the above coments. It is useful, however, to consider specific systems and see how the above ideas apply.

As we have already indicated, aging in Mi-base alloys containing only Al is arginal, whereas the response in related comercial alloys is more aubtantial. This is a result of the increased entropy of aixing, at least in part.

Mile liatted age hardening is possible in both the Cu-Fe and the Cu-Co system, the addition of III to elther oysten provides very extensive regions where spinodal decomposition can occur, a direct result of the higher atual solubility of $\mathrm{MI}$ with $\mathrm{Pe}, \mathrm{Cu}$, and $\mathrm{Co}$. The coherency stress decreases with $\mathrm{Mi}$ content. Purtber, some compositions can be further strengthened by the formation of the ordered phases $\mathrm{Ni}_{3} \mathrm{Fe}$ and Mi 3 Co. The addition of Au to Cu-Ag alloys is very alnilar, and, in fact, there are eny such ternary systeas, all of which can be identified from the respective binary phase diagrans.

As further exaples of these ideas, we wish to consider two practices in the glass industry. In making glass it is of utwost inportance that no crystalline phase form during cooling. The presence of a number of compoients in the liquid normally lowers the activity of each oxide, reducing the tendency to fora crystalline phases. Purther, it is Interesting that in the case of oxides there are any ternary conpounds (that is, gtructures containing three oxides), so little wy be gained by going from a binary to a ternary composition, but one reduces the potential to form crystalline phases as one adds wore components. Many factors go into deternining the various gless compositions, but so far as we are aware, it has not been recognized that oluply having any conponents will increase the stability of the glass relative to the cryetalline phases.

Certaln glasses develop literesting opitcal properties by the precipitation of anall asounts of a crystalline phase, such as Cu or Au. The glase is wde with a call, soluble addition of Al or $\mathrm{Cu}$, cooled to a low temperature to mucleate the setallic phase, and then aged at an 
elevated teaperature to grow the particles to the of ze to interact stroagly wth light. That the component has a eparingly anll solubiIity means that the heat of solution is so high that the high degrees of supersaturation required for mucleation an be obtained. Fecthape almost any material that has 8 . anl solubility could be sinilarly used.

A basic tenet of this report is that thernodynatic calculations provide a powerful appronch in de.eloping useful precipitation systens In higher order systens. One example is the calculation of the solubility of netastable phases. Such phases are often of concern during the early stages of precipitatior, and experinental nethods have a linited capacity to address this question. We have done thernodyanate calculatlons on the bec phase in the $0-2 x-m b$ sjsten and were rather wo successful than previous investigators in understandis the complex trangformations that occur in this syste. 6 In particular, ce dewonstrated that the accepted phase diagran is highly suspect. Our calculations Included the effect of coherency. In a study on the $\hat{c} ;-A u$ sgsten, 7 we have shown the coasiderable care and effort that can be required to properly understand what is taking plece. Por this systen the coherency and interfacial energies were responsibie for the observed two-phace field being oaly one-fourth as wide as the true equilibriu field.

The accepted way to predict the oscurrence of the sigan phase in superalloye is the Phacomp nethod.8 The electron-to-aton ratio of the eatrix is calculated, and when it corresponds to positions to the left of Pe in the periodic table, sigan can form. Although this wethod is simple and useful, it cannot in principle be exact. In contrast, a calculation based upon the thernodynenics is in principle exact, although its inplementation requires that we have adequate thermodynanic Information. Rut having this information one can calculate the asount of the siga phace as a function of tenperature. Recently the problen

7R. O. H11lians, unpublished study of Cu-Au system.

${ }^{8}$ C. T. Sine, the Superalloye, ed. by C. T. sine and W. C. Hagel, W1ley-Interscience, Ilaw York, 1972. 
has been reformilated in teras of a pseva.iquacernary phase diagrao.9 While this has been shown to give superior results compared with the Phacong nethud it cannot be exact in principle.

In a way it 18 unfortunate that the Pthacosp nethod works as well as It does because this leads some people to believe that it has sone theoretical basis. It does not.

Recently Dreshfield and Wallace 10 carried out an extensive experiseatal progra to deteraine the anount of $\mathrm{M}_{3} \mathrm{Al}$ in various superalloy compositions with $\&$ ir. components and rationalize the results in terns of an equation. We do not question that such phase boundaries can be adequately represeaced analyically, but the selection of an adequate expression is difficult. 3uch expressions are also difficult to use. A representation based on thermodyanics will provide the phase equilibria, lacluding netastable equilibria, as well as the activities of the components and the driving force for decomposition.

We are by no means suggesting that alloy design can be totally based upon thermodynapics. In the first place, the calculations will selion be of sufficient accuracy. But what one expects is that the calc:-lations will help to select changes in composition to adify the solubility, the cohsrency strains, and possibly the degree of order and to elininate unisanted phases.

In tiis connection certain coments are wrranted concerning prec1pitation. Oae ay use any nuber of measurewents to wonticor the early steges of precipitation, also known as zone foration, preprecipitation, or spinodal decomposition, but the identification of the new phase renalns difficult. Election microscopy is of limited use because of the sallness of the Initial precipitate particles. There wat be changes In the diffuse $x$-ray scattering, but they may be too meak to detect, and in

9.. S. Machl In and J. Shao, "SIGA-SAPE: a Phase Digram Approach to the Signa Phase Problew in Mi Base Superalloys," Mtall. Trans. 9A: $561-68$ (1978).

10. L. Dreshfield and J. F. Wallace, "The Gama-Gana Prine Region of the $\mathrm{N1}-\mathrm{Al}-\mathrm{Cr}-\mathrm{T} 1-\mathrm{H}-\mathrm{H}_{0}$ Systen at $850^{\circ} \mathrm{C}$," Metall. Trane. 5: 71-78 (1974;. 
any case their interpretation ay well prove difficult. Wevertheless, x-ray diffraction realins the oore definitive tool. An adequate thernodyonic representation can be a poverful tool. The precipitated phase ay be classified as:

A. an equilibriu phase,

B. an equilibriu phase for the systen but netastable at the given composition,

C. a structure not found in the equilibriun systen.

As we have already indicated, the precipitate is expected to be coherenc in the early stages, and there will be an attendant compositional codiifcation, but to refer to a coherent phase as a transition phase is, we bel feve, poor nomenclature. To call structures B or C transition structures can be aisleading because, although with tine these give wy to structure $A$, there need be no structiral relation between the successive stages. A case in point is the Al-Ag systen, In whth the first stage consists of the Af-rich fcc phase being replaced by a coherent hcp phase, which presinably nucleates independently on dislocation loops. The structure that forns first is likely to be the one that wost reseables the matrix and thus can nucleate nost readily; this accounts for the occurrence of structures $B$ and ' $C$. A reasonable number of structures of class B are known but for class C the situation is understandably less well documented because the structure cannot be studied in the bulk. The precipitation of $\mathrm{Cr}$ from $\mathrm{Cu} i s$ belleved to be class $\mathrm{C}$ since we doubt that the inftial prectpitate is bcc, but the actual structure and 1 s composition have not been established.

To show how incorrect conclusions can survive a long tine, consider the case of Al contsining Cu. It is still generally believed that the Initial stage consists of the forwation of ihin plates of pure copper to be followed by ordering. Yet in 1952 Meifering ${ }^{11}$ concluded that the free energy curve is, as we have shown it in P1g. 5, such that the In1tal precipitate 1s a solid solution containing about $25 \%$ Al atoms. The precipitate 18 observed to order ideally as $\mathrm{Cu}_{3} \mathrm{Al}$. This order may exist

J. L. Melfering, Rev. Metall o' (Paris) 49: 906 (1952). 
In the inftial precipitate but, if 00 , the sallwess of the doalus within each plate prevents its detection.

Sunner an comecustows

1. Oaly a sall fraction of the binary syatens possess the particular conblantioas of thermodynalcs and structures that lead to useful precipitation hardening. In spite of the fact that me'h work on binary phases diagrans reanins to be done, we expect few additional useful syotese to energe. This work has provided infornation about shat kinds of systens should shov pronice.

2. Wile precipitation alloys containing three or wre conposents have been developed, we believe that a rast potential still exists in this area. The difficulty is that vithout some guidance the scope of the problem can be overthelning.

3. The thernodyanics of alloys is suffictently well developed to provide this guidance. As one progresses to core ciaplex svatens, one nust depend increasingly on thernodynaics if one is to retain any conprehension of what is happening.

4. We have shown that having any components in oxide welts contributes to the ease of retaining the welt as a glass. Should one want to form a dilute precipitate, one picks a substance of such sparing solubility that high degrees of supersaturation can be obtained.

\section{ACXIOULEDEATSS}

We are appreciative of the nuserous constructive coments recelved fron C. T. LIu and J. M. Leitnaker, the typing by Raren Perry, and the editorial assistance of 518 Peterson. 
0.21L-5537

Distribution

Category UC-25

\section{InIEnIAL DISTISUTIOA}

1-2. Central Research Library

3. Doconent Reference Section

4-5. Laboratory Decorde Departent

6. Laboratory Records, OUI BC

7. OUll Patent Section

3. P. Angellat

9. R. G. Dergaren

10. D. A. Cemonteo

11. G. H. Clark

12. R. H. Cooper

13. S. As David

14. D. S. Easton

15. Ro. Partell

16. J. S. Paulkner

17. G, R. Gessel

18. Ho Lo Grossbeck

19. D. E. Larasyn

20. R. W. Beadricke

21-22. H. R. HAll

23. J. D. Holder

24. W. W. Harris

25. J. A. Horak

26. E. A. Renik

27. J. H. Koger

28. J. R. Telser

29. C. C. Koch

30. R. J. Lauf

31. Ene H. Lee
32. J. H. Leitmaker
33. C. T. Lu
34. K. C. Lu
35. C. J. Lons
36. P. J. Meinez
37. C. S. Morgan
38. R. E. Favel
39. H. E. Deesor
40. T. C. Deiley
41. A. F. Doucliffe
42. A. C. Schaffhauser
43. J. E. Selle
44. V. K. Sikle
45. P. S. Sklad
46. C. M. Slaughter
47. C. J. Sparke, Jr.
48. J. O. Stiegler
49. R. W. Surindenan
50. P. P. Tortorelli
51. R. A. Vanderneer
52-76. L. O. Hillian
77. F. H. Young, Jr.
78. R. H. Balluffi (Consultant)
79. A. Io Denent, Jr. (Consultant)
80. H. R. Hibbard, Jr. (Cocsultant)
81. B. H. Kottcap, Jr. (Consultant)
82. M. J. Mayfield (Consultant)
83. T. Stringer (Consultant)

\section{ExTERMaL DISTRIBUTIOA}

84-85. DOE Division of Materials Sciences, Washington, DC 20545

86. Dor Oak Ridge Operations Office, P.0. Dox E, Oak RIdge, TI 37830

Ansistant Manger, Eoergy Research and Development

87-318. Technical Information Center office of Inforation Services, P.0. Dox 62, Oak Ridge, III 37830

For dietribution as shom in TID-45CO Distribution Category

UC-25 (Haterials). 